\title{
Caminhos para um feminismo decolonial ${ }^{*}$
}

\author{
Jessica Antunes Ferrara** \\ Silvina Liliana Carrizo***
}

\section{Resumo}

Este estudo propõe uma descentralização epistêmica do movimento feminista, de modo que seja possível pensarmos em caminhos para uma prática feminista decolonial. Assim, é necessário lançarmos um olhar crítico ao projeto histórico do capital, cujas categorizações sociais tornam invisíveis as experiências e demandas de mulheres não-brancas. Os estudos sobre gênero e colonialidade elaborados por Rita L. Segato (2011) e María Lugones (2008) serão substanciais para uma profunda análise do sistema colonial de gênero, desarticulando classificações colonialistas e propondo alternativas particulares às mulheres da América Latina.

Palavras-chave: Prática Feminista Decolonial, Colonialidade, América Latina.

\footnotetext{
* Recebido em 15 de janeiro de 2020, aceito em 10 de julho de 2020.

${ }^{* *}$ Doutoranda em Letras: Estudos Literários, pela Universidade Federal de Juiz de Fora, Juiz de Fora, MG, Brasil. j.antunesferrara@gmail.com / http://orcid.org/0000-0003-4763-8936

${ }^{* * *}$ Professora Associada da Universidade Federal de Juiz de Fora, na Faculdade de Letras, na Licenciatura em Espanhol e suas Literaturas e na Pós-graduação em Letras: Estudos Literários, da Universidade Federal de Juiz de Fora, Juiz de Fora, MG, Brasil. silvinalit@gmail.com / https://orcid.org/0000-0002-8340-9754
} 
Paths to a Decolonial Feminism

\section{Abstract}

This study proposes an epistemic decentralization of the feminist movement to allow considering routes to a decolonial feminist practice. This requires taking a critical look at the historical project of capital, whose social categorizations make the experiences and demands of non-white women invisible. The studies on gender and coloniality by Rita L. Segato (2011) and María Lugones (2008) provide substantial support to an in-depth analysis of the colonial gender system, dismantling colonialist classifications and proposing specific alternatives for Latin American women.

Keywords: Decolonial Feminist Practice, Coloniality, Latin America. 


\section{Introdução}

Ao longo de sua trajetória como pensador e sociólogo, o peruano Aníbal Quijano desenvolveu, em conjunto com um grupo considerável de pesquisadores e pesquisadoras ${ }^{1}$, uma proposta de virada radical na compreensão da história dos países da América Latina, bem como do papel de nosso continente na recomposição daquilo que consideramos como mundo. De acordo com a antropóloga Rita Segato (2014), a perspectiva crítica da colonialidade do poder rompe drasticamente com os postulados eurocentristas encontrados nos campos da História, da Filosofia e das Ciências Sociais da América Latina, além de ser, em si, uma perspectiva que impulsiona e inspira novas formas de orientação dos movimentos sociais e políticos nesse contexto.

O chamado giro decolonial ou a decolonialidade (Maldonado-Torres, 2006), muito embora também apresente uma nova maneira de pensar a ordem e a constituição das relações mundiais, não é exatamente igual àquilo que se conhece como pós-colonialismo. As teorias decolonial e póscolonial se diferem não por proporem modos de leitura, análise e ação díspares, mas sim por partirem de perspectivas diferentes; a primeira é fundamentalmente elaborada no seio do contexto social e político latino-americano, e, assim, não pode ser equalizada às percepções específicas produzidas a partir do pós-estruturalismo francês em países anglo-saxões. Castro-Gómez e Grosfoguel (2007) apontam, ainda, uma divergência fundamental entre decolonialidade e estudos pós-coloniais, posto que estes últimos acabam sucumbindo a um "reducionismo culturalista". Para esses autores, a questão é que os estudos culturais e pós-coloniais ignoraram a impossibilidade de se compreender "o capitalismo global sem levar em conta a maneira como os discursos raciais organizam a população mundial em uma divisão internacional do trabalho que tem implicações econômicas diretas" (Castro-Gómez; Grosfoguel, 2007:16, tradução nossa ${ }^{2}$ ). Isso significa que, da mesma maneira que os estudos pós-coloniais consideram o papel fundamental das epistemes, a perspectiva decolonial também o faz, com a diferença de que esse papel se entrelaça, diretamente, com os processos econômicos e políticos. Assim, a crítica proveniente do pós-colonialismo entende o sistema mundial como com sistema de significações culturais no qual há marcas, rastros, heranças de um sistema colonial. O poder, aqui, muda suas configurações e passa a agir culturalmente ${ }^{3}$. Em contrapartida, a perspectiva decolonial não admite ter havido significativa mudança na forma do exercício do poder, não existindo uma sociedade economicamente descolonizada na qual apenas os bens culturais se encontram sob o domínio do Norte. Colonialismo, capitalismo e racialização dos povos, nesse viés, são uma só coisa.

A partir desse entendimento, vê-se que, por exemplo, a dominação e exploração econômica do Sul pelo Norte é dada através de uma base étnico-racial que perdura desde o século XVI, momento de sua instituição. É possível depreender, então, a ideia basilar que constitui a noção de "colonialidade do poder": o mundo não foi, de forma alguma, descolonizado, e o que corrobora tal

\footnotetext{
1 Aníbal Quijano é um dos nomes mais proeminentes do chamado grupo "modernidade/colonialidade", o qual se organiza em volta da perspectiva decolonial desde o final dos anos 1990. Também fazem parte do grupo Walter Mignolo, Mónica Espinosa, Edgardo Lander, Ramón Grosfoguel, Juliana Flórez-Flórez, Fernando Coronil, Santiago Castro-Gómez, entre outros e outras.

2 “[...] el capitalismo global sintenerencuentael modo como los discursos racialesorganizan a lapoblacióndel mundo en una división internacional deltrabajo que tienedirectasimplicaciones económicas" (Castro-Gómez; Grosfoguel, 2007:16). Toda tradução da língua castelhana para a língua portuguesa será de nossa autoria.

3 Isso pode ser notado na explanação de Stuart Hall, expoente da teoria pós-colonial, em sua obra Da Diáspora: Identidades e Mediações Culturais (2003:56): “[...] o 'pós-colonial' marca a passagem de uma configuração ou conjuntura histórica de poder para outra. [...]. No passado, eram articuladas como relações desiguais de poder e exploração entre as sociedades colonizadoras $e$ as colonizadas. Atualmente, essas relações são deslocadas e reencenadas como lutas entre forças sociais [...] no interior da sociedade descolonizada, ou entre ela e o sistema global como um todo".

4 A regionalização Norte-Sul faz referência à atual divisão socioeconômica observada a nível mundial. Os países que compõem o eixo Norte são aqueles que historicamente exploram e acumulam riquezas, ao passo que aqueles que compõem o eixo Sul são aqueles que são explorados e vivem sob o processo contínuo de colonização, ou, mais precisamente, sob a colonialidade do poder.
} 
afirmação é o fato de a racialização dos povos permanecer, até os dias atuais, de maneira naturalizada (Castro-Gómez; Grosfoguel, 2007; Quijano, 2014 ${ }^{5}$ ).

A colonialidade, portanto, não se findou com a ruptura do colonialismo. Sabe-se que o primeiro processo de descolonização, o qual teve início no século XIX nas colônias espanholas, foi um processo incompleto, haja vista tenha conquistado apenas a independência jurídico-política dos espaços explorados. Em contrapartida,

A segunda descolonialização - à qual aludimos à categoria de decolonialidade - terá de abordar a heterarquia das múltiplas relações raciais, étnicas, sexuais, epistêmicas, econômicas e de gênero que a primeira descolonialização deixou intacta. Como resultado, o mundo do início do século XXI precisa de uma decolonialidade que complemente a descolonização realizada nos séculos XIX e XX. Ao contrário dessa descolonialização, a decolonialidade é um processo de ressignificação a longo prazo, que não pode ser reduzido a um evento político-jurídico (CastroGómez; Grosfoguel, 2007:17, grifo nosso ${ }^{6}$ ).

Para que se tome consciência dessa ressignificação é necessário, antes, compreender de que forma essa colonialidade se apresenta, isto é, o que é essa estrutura e o que permite sua manutenção até os dias atuais. Segundo Quijano (2014:1007), "a ideia de raça é, com toda segurança, o mais eficaz instrumento de dominação social inventado nos últimos 500 anos". Assim, o conceito de raça atua como regulador das relações de poder criadas entre os povos. Na medida em que tal concepção ia sendo imposta, foi se tornando o critério básico de classificação social de toda a população mundial, e a partir dessa mesma ideia foram criadas e distribuídas as principais novas identidades sociais e geoculturais do planeta. A Europa como centro do poder mundial capitalista $e$ a consequente divisão social do trabalho foram movimentos históricos que se desenvolveram alicerçados na disseminação da ideia de raça, que também foi fundamental para se traçar "as diferenças e distâncias específicas na respectiva configuração específica de poder, com suas cruciais implicações no processo de democratização de sociedades e estados e de formação de Estados-nação modernos" (Quijano, 2014:100). Com isso, é perceptível que a noção de raça permeia todos os âmbitos de poder no padrão imposto pelo sistema do capital, o que significa que a colonialidade consiste na base do padrão de poder mundial capitalista, colonial/moderno $e$ eurocentrado.

É precisamente a racialização dos povos, pois, que define a colonialidade do poder, cujos atributos são duradouros e atuais, além de ultrapassarem o próprio colonialismo que a originou $e$ que a possibilitou ser mundialmente imposta. Quijano lembra que, apesar de o racismo das relações comuns e cotidianas não ser a única forma de manifestação da colonialidade do poder, ele é, decerto, a forma mais perceptível e onipresente, e, portanto, se apresenta como o principal campo de conflito do debate. É importante afirmar que, mesmo com as conquistas obtidas através das lutas antirracistas, a estrutura social racista, a qual se encontra nas bases de cada Estado-nação, continua a agir. No contexto do Peru, conforme exemplifica Quijano, "a prática da discriminação racista agora exige mascaramento, muitas vezes, se não sempre, por trás de códigos sociais que se referem a diferenças na educação e na renda que, neste país, são precisamente uma das mais claras

\footnotetext{
${ }^{5}$ Opta-se, aqui, por marcar o ano de publicação original dos textos de Quijano por estes apresentarem uma gama de edições desde o momento de suas produções. Importa, igualmente, situar na história a gênese das teorizações sobre a colonialidade do poder.

6 " [...] la segunda descolonialización — a la cual nosotros aludimos con la categoría decolonialidad— tendrá que dirigirse a la heterarquía de las múltiples relaciones raciales, étnicas, sexuales, epistémicas, económicas y de género que la primera descolonialización dejó intactas. Como resultado, el mundo de comienzos del siglo XXI necesita una decolonialidad que complemente la descolonización llevada a cabo en los siglos XIX y XX. Al contrario de esa descolonialización, la decolonialidad es un proceso de resignificación a largo plazo, que no se puede reducir a un acontecimiento jurídicopolítico" (Castro-Gómez; Grosfoguel, 2007:17).

7 "La idea de raza es, con toda seguridad, el más eficaz instrumento de dominación social inventado en los últimos 500 años" (Quijano, 2014:100).

8 "[...] las diferencias y distancias específicas en la respectiva configuración específica de poder, con sus cruciales implicaciones en el proceso de democratización de sociedades y Estados y de formación de Estados-nación modernos" (Quijano, 2014:100).
} 
consequências das relações sociais racistas" (2014:101 $\left.{ }^{9}\right)$. Percebe-se, então, que a perpetuação da estrutura racista, isto é, da admissão da raça como um fenômeno biológico que tem consequências na organização das relações de poder entre as pessoas, garante a eficácia da dominação social. É necessário, portanto, que compreendamos que a raça é uma construção ideológica que não corresponde a estrutura biológica do ser, e sim à "história das relações de poder no capitalismo mundial, colonial/moderno, eurocentrado" (Quijano, 2014:102 ${ }^{10}$ ).

$\mathrm{O}$ padrão de classificação social observado ainda hoje, o qual origina-se no processo de colonização das Américas, permite a associação entre mercantilização da força de trabalho e a hierarquização da população mundial em termos de raça. As crises desse padrão ocorrem de maneiras e em tempos diferentes em cada região do mundo capitalista, sendo que em alguns lugares as vítimas de racismo avançam em suas resistências, ao passo que em outros lugares não encontram espaço algum. De qualquer modo, Quijano (2014) postula que são exatamente essas descontinuidades que sustentam a crise, cujo fruto é o debate sobre a questão da raça $-e$, como será visto posteriormente, sobre a questão de gênero.

Apesar de a ideia de raça ter sido construída desde os primórdios da colonização, dada sua eficácia em servir aos projetos exploratórios europeus, foi apenas a partir do século XIX que se iniciou uma teorização sobre essa concepção e sua associação ao desenvolvimento dos povos. Foi com a criação da "América" que o "outro lado" pôde se transformar em um novo eixo central do comércio mundial no séc. XVI —ou seja, a colonização foi fundamental para que o projeto histórico do capitalismo prevalecesse (Coronil, 2005). No entendimento de Quijano,

os povos e os grupos dominantes que participavam do controle desse eixo partiram brevemente para a formação de uma nova região histórica, e ali se constitui "Europa" como uma nova identidade geocultural e como centro hegemônico do nascente capitalismo mundial. Essa posição permitiu aos europeus, em particular aos da Europa Ocidental, impor a ideia de "raça" na base da divisão mundial do trabalho, e de intercâmbio na classificação social e geocultural da população mundial $\left(2014: 107^{11}\right)$.

Logo, é a criação da América e do modelo de poder colonial/capitalista que possibilitou a constituição da Europa e do eurocentrismo - um eufemismo da colonialidade do poder. A condição da Europa como centro hegemônico dessa dita "modernidade" foi, portanto, o que permitiu com que ela também detivesse a hegemonia das produções de saberes que dizem respeito a toda essa complexa experiência histórica. Com isso, uma visão eurocêntrica/colonial é difundida como única, excluindo todas as outras narrativas e possibilidades de saberes. De acordo com Segato (2019), com o processo inicial de conquista, toda a forma de se olhar e representar o mundo ficou condicionada à percepção do europeu. A partir dessa única percepção foram construídas categorias através das quais nossa história é narrada até hoje; ou seja, reproduz-se o discurso colonizador através da repetição de categorias criadas e difundidas pelos conquistadores $e$ colonizadores das Américas. Nas palavras de Quijano,

a modernidade, como padrão de experiência social, material e subjetiva, era a expressão da experiência global do novo poder mundial. Mas sua racionalidade foi produto de elaboração

\footnotetext{
9 “[...] lapráctica de ladiscriminación racista requiereahora ser enmascarada, confrecuencia si no siempreconéxito, detrás de códigos sociales referidos a diferencias de educación y de ingresos que en este país son, precisamente, una de las más claras consecuencias de relaciones sociales racistas" (Quijano, 2014:101).

10 "[...] historia de las relaciones de poder en el capitalismo mundial, colonial/moderno, eurocentrado" (Quijano, 2014:102).

11 "Los pueblos y los grupos dominantes que participabandelcontrol de dichoejetendieron pronto a laformación de una nuevaregión histórica y allí se constituyó "Europa" como una nuevaidentidadgeocultural y como centro hegemónico delnaciente capitalismo mundial. Esa posiciónpermitió a loseuropeos, en particular a los de Europa Occidental, imponerlaidea de "raza" enla base de ladivisión mundial de trabajo y de intercambio y enlaclasificación social y geocultural de lapoblación mundial” (Quijano, 2014:107).
} 
europeia. Quer dizer, foi a expressão da perspectiva eurocêntrica do conjunto da experiência do mundo colonial/moderno do capitalismo $\left(2014: 107^{12}\right)$.

Algo fundamental para essa perspectiva eurocêntrica do conhecimento foi o dualismo, isto é, a separação radical entre sujeito/razão e corpo/objeto. Apregoada por René Descartes, a concepção dualista permitiu uma sistematização do pensamento europeu ocidental em termos de raça $e$ também de gênero. Silvia Federici afirma que:

Com a instituição de uma mente hierárquica entre a mente e o corpo, Descartes desenvolveu as premissas teóricas da disciplina do trabalho requerida para o desenvolvimento da economia capitalista. A supremacia da mente sobre o corpo implica que a vontade pode, em princípio, controlar as necessidades, as reações e os reflexos do corpo; que pode impor uma ordem regular sobre suas funções vitais e forçar o corpo a trabalhar de acordo com especificações externas, independentemente de seus desejos (2017:271).

Essa mecanização do corpo, que passa a se resumir em força de trabalho, foi fato imprescindível para o desenvolvimento de um novo padrão de poder mundial, o capitalismo. $\mathrm{O}$ desenvolvimento da racionalização científica construiu um protótipo de sujeito a partir da homogeneização dos comportamentos sociais. De acordo com Coronil (2005), das colônias da Europa usurparam-se mão de obra e recursos naturais, e a relação com esse "outro" colonial, que apresentava variedades culturais àquela europeia, somada à racionalização e à noção de "homem cartesiano", insuflou a compreensão dos territórios europeus como redutos de um padrão de humanidade. Nesse sentido, a Europa passa a se constituir como "portadora de uma religião, uma razão e uma civilização superiores encarnadas [apenas] pelos europeus" (Coronil, 2005:52). Daí a questão da invenção da raça, o que permitiu e permite a legitimação dessa superioridade. Para além disso, os colonizadores ainda imputaram sobre os povos explorados suas percepções em relação ao gênero. A invenção da raça e o recrudescimento da desigualdade e consequente violência de gênero foram bagagens culturais trazidas da Europa, visando a destruição da vida comunitária em prol de um interesse econômico específico (Federici, 2017). Ainda dentro do dualismo cartesiano, vê-se o corpo tornando-se natureza e, consequentemente, sexo e raça. Assim,

o papel da mulher, o "gênero feminino" está mais estreitamente ligado ao "sexo", ao "corpo", portanto. Segundo isso, é um "gênero inferior". De outro modo, "raça" é também um fenômeno "natural", e algumas "raças" estão mais próximas da "natureza" que outras, e são, pois, "inferiores" àquelas que conseguiram chegar o mais longe possível do estado de natureza (Quijano, 2014:108 ${ }^{13}$ ).

O processo de naturalização do racismo e do sexismo permite com que sejam eles, portanto, elementos estruturantes de nossa sociedade. Tal naturalização ocorre, atualmente, de maneira dissimulada, apoiando-se em discursos sobre a liberdade de escolha individual e nas Constituições Federais de cunho liberal promulgadas na maioria dos países tanto do Norte quanto do Sul ${ }^{14}$. A legislação é utilizada de forma manipuladora no sentido de que, se não existe mais um documento que legalize a escravidão ou a proibição de determinados comportamentos $e$ atitudes de mulheres, então é certo que o racismo, a exploração e a desigualdade entre gêneros foram práticas banidas. Entretanto, no contexto da realidade material, não é o que se observa. As estruturas racistas e

\footnotetext{
12 "La modernidad, como patrón de experiencia social, material y subjetiva, era laexpresión de la experiencia global delnuevo poder mundial. Pero suracionalidadfueproducto de laelaboracióneuropea. Es decir, fuelaexpresión de la perspectiva eurocéntricadel conjunto de la experiencia del mundo colonial/moderno del capitalismo" (Quijano, 2014:107).

13 'El rol de lamujer, el 'género femenino' está másestrechamente pegado al 'sexo', al 'cuerpo' pues. Segúneso es un 'género inferior'. De otro lado 'raza' es tambiénunfenómeno 'natural' y algunas 'razas' están más cerca de la 'naturaleza' que otras y son, pues, 'inferiores' a las que han logrado alejarselo más posibledel estado de naturaleza" (Quijano, 2014:108).

${ }^{14}$ Segato (2019) salienta que os sujeitos fundadores das repúblicas do Sul são sujeitos inseguros em todos os aspectos; racial, sexual, de gênero, e até mesmo no aspecto humano em geral. Por isso, ainda segundo a antropóloga, o sujeito crioulo é um sujeito racista, homofóbico, misógino e especista. Em detrimento disso, nossa independência é incompleta, visto que permanecemos dependentes, de forma naturalizada, da estrutura colonialista.
} 
sexistas continuam sustentando as relações entre os povos e entre os sujeitos, além de ainda servirem de base para a manutenção do sistema capitalista.

\section{Crítica ao feminismo eurocêntrico-liberal}

Conforme exposto, a concepção da colonialidade do poder oferece uma percepção de que a descolonização territorial não aniquilou a colonialidade, a qual se apresenta como um contínuo padrão básico de poder a nível mundial. Decerto, é essa continuidade que precisa ser compreendida e desarticulada para que então possamos vislumbrar novos caminhos de organização social e política. O eixo central que assegura essa colonialidade permanente é o conceito de raça. Essa concepção criada e imposta é o centro da continuidade do processo de colonização porque é ela que faz com que a estrutura de poder permaneça intacta por ter sido naturalizada e biologizada (Quijano, 2014; Segato, 2019).

Vimos alhures que o atual padrão de classificação social permite com que seja efetuada uma associação entre mercantilização da força de trabalho e hierarquização da população em termos de raça e também de gênero. Não há meios de se conceber, principalmente nos contextos múltiplos da América Latina, um feminismo que não perpasse pelas questões de raça e classe, questões medulares se pensarmos no sistema colonialista/capitalista. Seria insuficiente uma luta que pretendesse homogeneizar as experiências das mulheres e que tampouco se atentasse às dissimulações e limitações das leis e da democracia burguesa.

De acordo com Walter D. Mignolo (2008), a matriz colonial de poder se apresenta a partir da articulação de quatro eixos: (i) controle da economia, (ii) controle da autoridade (formas e práticas de governo), (iii) controle dos papeis de gênero e do exercício da sexualidade e (iv) controle do conhecimento e das constituições das subjetividades. Nesse sentido, um feminismo eurocêntricoliberal não pode dar conta das consequências deixadas pela articulação de tais eixos de controle nos espaços que mais são afetados pelo padrão de poder mundial capitalista colonial/moderno, haja vista as demandas das mulheres que encontram, dentro desse padrão, privilégios epistêmicos serem fundamentalmente diversas das mulheres atingidas de maneira direta pela racialização imposta pela colonialidade. Os corpos e a constituição das subjetividades das mulheres latinoamericanas não podem ser apagados por um movimento homogeneizante; é necessário que se vá além, investigando como as políticas de racialização e empobrecimento da América Latina estão, desde o século XVI, definindo os corpos e as subjetividades nesses espaços (Miñoso, 2009:40).

Conforme alerta Quijano (2014), a raça, desde os primórdios da colonização, tornou-se o principal critério de distribuição da população mundial em fileiras, lugares e funções dentro da estrutura de poder do padrão colonialista. A questão do trabalho foi também articulada nessa perspectiva, e, por isso, capitalismo é outro nome que se dá a colonialidade. Durante o processo de construção histórica da América, as mais diversas práticas de controle e exploração de trabalho, bem como de controle da produção, apropriação e distribuição dos produtos foram desenvolvidas "ao redor da relação capital-salário (de agora em diante, capital) e do mercado mundial. Acabaram incluídas a escravidão, a servidão, a pequena produção mercantil, a reciprocidade e o salário" (Quijano, 2014:112 ${ }^{15}$ ). Tais formas de controle eram totalmente novas, ao menos da maneira pela qual estavam se desenvolvendo, posto que seu componente histórico e sociológico não era o mesmo das formas estabelecidas em outros tempos. Essas novas formas/práticas foram deliberadamente estabelecidas e organizadas com a finalidade de produzir bens para o mercado mundial, de modo que todas elas se encontravam articuladas ao capital e ao seu mercado. Essa estrutura conjuntamente sistematizada permitiu a instauração de um padrão global de controle do trabalho, de seus recursos e de seus produtos. Dessa maneira, estabelecia-se o capitalismo mundial. Nele, as novas identidades políticas criadas pela categorização dos povos mediante a ideia de raça passaram a ser associadas à natureza das funções e dos lugares. Raça e divisão do trabalho se tornaram associações estruturais fundamentais para o projeto histórico colonial-capitalista, e, por isso, acabam por se reforçarem mutuamente. É o que se pode chamar de "divisão racial do

\footnotetext{
15 “[...] alrededor de larelación capital-salario (enadelante capital) y del mercado mundial. Quedaronincluidaslaesclavitud, laservidumbre, lapequeñaproducción mercantil, lareciprocidad y elsalario” (Quijano, 2014:112).
} 
trabalho" (Quijano, 2014:113 ${ }^{16}$ ), que teve início no interior do capitalismo colonial/moderno e que se mantém até os dias atuais.

A partir do exposto, percebe-se a impossibilidade de desconsiderar tais articulações históricas quando pensamos acerca da questão de gênero. É inviável generalizar demandas e homogeneizar um grupo sob o epíteto de "mulheres"; há que se ter em conta o processo de divisão racial do trabalho. Na visão da cientista política Flávia Biroli (2018), é a partir da conjugação entre gênero, classe e raça que as posições relativas se estabelecem de fato. Para a autora, há também uma divisão sexual do trabalho, a qual atinge homens e mulheres em conjunto, considerando suas posições de classe e, ademais, o racismo estrutural. Dessa maneira, não é razoável "pressupor que os privilégios estão sempre entre os homens, $e$ as desvantagens $e$ as formas mais acentuadas de exploração, entre as mulheres" (Biroli, 2018:22). Atualmente, observa-se que a hierarquia da divisão sexual (e racial) do trabalho é dada da seguinte maneira: homens brancos, mulheres brancas, homens negros e, por fim, mulheres negras. Isso mostra que o gênero não pode ser pensado de forma apartada dos problemas de raça e classe social, tampouco deve ser visto como acessório dessas variáveis. Em outras palavras, "a divisão sexual do trabalho é um lócus importante da produção do gênero. O fato de ela não incidir igualmente sobre todas as mulheres implica que a produção do gênero que assim se dá é racializada e atende a uma dinâmica de classe" (Biroli, 2018:23, grifos da autora). Torna-se inconcebível, assim, um sujeito do feminismo eurocêntrico e liberal, agrupado pura e simplesmente na categoria genérica "mulheres".

No primeiro capítulo de Problemas de gênero: feminismo e subversão da identidade (2017a:17), Judith Butler problematiza o conceito de "mulheres" como sujeito do feminismo. Segundo a filósofa,

se alguém "é" uma mulher, isso certamente não é tudo o que esse alguém é; o termo não logra ser exaustivo, não porque os traços predefinidos de gênero da "pessoa" transcendam a parafernália específica de seu gênero, mas porque o gênero nem sempre se constituiu de maneira coerente e consistente nos diferentes contextos históricos, e porque o gênero estabelece interseções com modalidades raciais, classistas, étnicas, sexuais e regionais de identidades discursivamente constituídas (Butler, 2017a:21).

A tentativa, portanto, de fixar a categoria homogênea "mulheres" acaba por corresponder às estruturas de poder as quais gostaria, antes, de combater. O problema consiste em buscar tornar a experiência do patriarcado uma experiência universal, desconsiderando ou pretendendo normatizar particularidades (Ferrara, 2019:27). Essa pretensão, no final das contas, violenta os sujeitos porque "deixa de responder à particularidade cultural e não reformula a si mesma em resposta às condições sociais e culturais que inclui em seu escopo de aplicação" (Butler, 2017b:17). Para além disso, o discurso que evoca valores universais atende à agenda política do liberalismo, servindo, na maior parte das vezes, "para neutralizar a compreensão do impacto que as desigualdades concretas têm sobre a possibilidade de agência autônoma dos diferentes indivíduos" (Miguel, 2014:64). Assim, ainda que tenham ocorrido avanços no que tange os direitos legais das mulheres, a neutralização das consequências que as desigualdades de gênero em interseção com as de raça e classe têm na vida de muitas mulheres não permite com que suas demandas específicas sejam atendidas. Isso significa, basicamente, que o sentido liberal suscitado pela dita "emancipação feminina" - de caráter eurocêntrico - perde sentido quando olhamos e compreendemos as formas atuais de exploração do trabalho, as quais, reitera-se, não nos permitem pensar em um grupo geral de "mulheres".

No contexto da colonialidade do poder, tornar invisível as experiências múltiplas das mulheres que se constroem em e habitam espaços como a América Latina a partir de uma universalidade criada e consagrada pela episteme europeia enfatiza a continuidade do processo de colonização iniciado séculos atrás. Se o feminismo eurocêntrico afirma que o problema da dominação de gênero é universal e, mediante isso, objetiva a transmissão do que considera

16 “[...] división racial deltrabajo” (Quijano, 2014:113). 
"avanços da modernidade" às vivências de mulheres não-brancas, então há aí uma prática colonialista. Isso porque tal feminismo

\begin{abstract}
mantém, assim, uma posição de superioridade moral das mulheres europeias ou eurocentrais, autorizando-as a intervir em sua missão civilizadora - colonial/modernizadora. Essa posição é, por sua vez, inevitavelmente a-histórica e anti-histórica, porque forclusa a história dentro do cristal de tempo lentíssimo, quase estagnado, do patriarcado, e sobretudo oclui a torção radical introduzida pela entrada do tempo colonial/moderno na história das relações de gênero (Segato, 2011:2317)
\end{abstract}

Compreende-se, a partir do exposto, o caráter colonial de um feminismo que se pressupõe universal, mas que parte de uma perspectiva limitada que não se atenta às experiências díspares das mulheres. Lembrando as postulações de Castro-Gómez (1998:122), é evidente a existência de um legado deixado pelo colonialismo territorial, o qual age desterritorializadamente sob modos como o da discursividade. Dessa forma, é preciso encarar a herança colonial de hipersexualização do corpo da mulher e suas interseções de raça e classe, herança essa inscrita principalmente, hoje, no discurso, permitindo sua continuidade. Nos livros oficiais de história aprendemos como os homens colonizam e exploram outros homens e mulheres, mas, embora exista, de fato, uma subjugação comum às mulheres em relação aos homens, deve-se empreender um movimento crítico no sentido de observar como essa hierarquia pode ser reproduzida entre as mulheres. Chandra T. Mohanty (2008:117 $\left.{ }^{18}\right)$ argumenta que os escritos feministas ocidentais, em sua maioria desenvolvidos nos Estados Unidos e na Europa Ocidental, constantemente colonizam discursivamente as heterogeneidades históricas e materiais das experiências das mulheres provenientes de espaços que malogram a continuidade da colonialidade, produzindo/representando "um composto singular, a 'mulher do terceiro mundo', uma imagem que parece construída de forma arbitrária, mas que leva consigo a entidade legitimadora do discurso humanista do Ocidente".

Ao retornar aos primórdios dos movimentos feministas latino-americanos, é notável a influência exercida pelo feminismo eurocêntrico, universalista, liberal, o qual se concentrava mais em direitos legislativos do que em práticas histórico-sociais que se apresentavam estruturais e fundamentais para a manutenção da ordem hierárquica dos papeis de gênero. É sabido que "os movimentos de origem europeia e estadunidense se organizavam em torno da reivindicação sufragista, e não tardou para que o protesto chegasse às mulheres latino-americanas, em especial às pertencentes à classe média-alta" (Ferrara, 2019:40), as quais, segundo Céli Regina Jardim Pinto, seriam as únicas a manter contato com as dinâmicas mundiais (2003:14). Nomes conhecidos, como o de Berta Lutz no Brasil, se destacaram na luta pelos direitos das mulheres, porém as questões sensíveis à raça e à classe social não pertenciam às suas agendas. É perceptível, ainda, o fato de que no contexto da América Latina o movimento feminista só fora admitido nessa sua fase embrionária justamente por se apresentar revestido de certo conservadorismo, atribuindo-lhe características bastante restritivas (Ferrara, 2019:40). Nesse sentido, ainda que muitos grupos de mulheres, desde aquele momento, já pensassem nos problemas trazidos por essa perspectiva conservadora, universalista, pouco disposta a mudar as estruturas de poder e nem um pouco atenta aos problemas de gênero que são perpassados por questões de raça e classe, a colonialidade do poder permaneceu sendo sustentada, obrigando-nos a lutar e reafirmar nossas existências dia após dia. Afinal, como pensar os feminismos a partir dessas (re)existências? Como pensar, portanto, em um feminismo decolonial?

\footnotetext{
17 "Sustenta, así, una posición de superioridad moral de las mujeres europeas o eurocentradas, autorizándolas a intervenir con sumisión civilizadora - colonial/modernizadora. Esta posición es, a su vez, inevitablemente a-histórica y anti-histórica, porque forclusa la historia dentro del cristal de tiempo lentísimo, casi-estancado, del patriarcado, y sobre todo ocluye la torsión radical introducida por la entrada del tiempo colonial/moderno en la historia de las relaciones de género" (Segato, 2011:23)

18 " [...] un compuesto singular, la 'mujer del tercer mundo', una imagen que parece construida de forma arbitraria pero que lleva consigo la firma legitimadora del discurso humanista de Occidente" (Mohanty, 2008:117).
} 


\title{
3. Aportes para um feminismo decolonial
}

A própria historicidade dos movimentos feministas que se desenvolveram na América Latina mostra as complexidades em se definir uma agenda que seja capaz de dar conta das inúmeras demandas das mulheres que fazem parte de um espaço múltiplo e heterogêneo como o é o latinoamericano. Cada país, com suas particularidades de formação nacional, possui urgências no que tange as questóes de gênero, principalmente quando interseccionadas às de raça, classe $e$ sexualidade. Como vivenciaram e repercutiram o processo colonizatório cada um a sua maneira, pode-se perceber certa multiplicidade no desenvolvimento das lutas feministas nesse contexto. A complexidade da formação nacional dos países da América Latina faz com que mesmo no interior de um único país seja possível encontrar uma fragmentação, "posto que cada demanda responderá a um fator determinado da exploração feminina local" (Ferrara, 2019:32).

$\mathrm{Na}$ esteira do pensamento decolonial, além das especificidades de demandas, existem pelo menos duas perspectivas que guiam as teorizações feministas. Embora conflitivas em relação a uma possivel gênese das dicotomias de gênero, ambas convergem ao postularem que a colonialidade do poder apresenta um sistema racializado de gênero, isto é, gênero e raça se entrelaçam e são inseparáveis para se pensar as experiências das mulheres não-brancas. Nesse viés, María Lugonese Rita Segato, autoras que tomaremos como representantes das duas perspectivas decoloniais dos feminismos latino-americanos, são, ambas, críticas ao feminismo eurocêntrico-liberal. O problema encontrado no feminismo hegemônico é, principalmente, conforme já mencionado, a homogeneização do grupo "mulheres". Da mesma maneira, com a racialização criada e imposta pela colonialidade, experiências dos povos trazidos de África, bem como dos múltiplos povos indígenas, foram violentadas a partir de uma redução e silenciamento das mesmas observado na homogeneização da criação de grupos simplistas como "negros" e "índios". Tais identidades globais, as quais correspondem aos processos de formações nacionais, se mostram congeladas $e$ atendem aos interesses universalistas dos Estados modernos liberais/neoliberais (Segato, 2007:21). Isso significa que, voltando à Quijano (2014), uma das estratégias da colonialidade do poder é a categorização. A partir do processo de conquista e exploração das Américas, toda a forma de representação do mundo e dos povos foi modificada mediante imposição violenta de categorias que até hoje são utilizadas para contar nossas histórias coletivas e pessoais. O problema apontado tanto por Segato $(2007: 20 ; 2019)$ quanto por Lugones (2008:24) é o fato de que tal categorização é, primeiramente, dada após os eventos, além de encobrir diferenças densas e complexas das culturas $e$ das vivências dos sujeitos, ocultando, ao considerarmos a intersecção de gênero e raça, as experiências de mulheres não-brancas. Lugones explica que as categorias que se pretendem homogêneas, as quais atendem a um padrão de poder de dominação colonial, selecionam os dominantes do grupo como sua norma. Assim, até mesmo a forma estratégica de interseção das categorias no momento das reivindicações dos direitos pode ser afetada caso não se lance um olhar crítico sobre essas construções categoriais. Isso ocorre porque

\begin{abstract}
"mulher" seleciona como norma as fêmeas burguesas brancas heterossexuais, "negro" seleciona machos heterossexuais negros, $e$ assim sucessivamente. Então, torna-se logicamente claro que a lógica de separação categorial distorce os seres e os fenômenos sociais que existem na interseção, como a violência contra as mulheres de cor. Dada a construção das categorias, a interseção interpreta erroneamente as mulheres de cor. Na interseção entre "mulher" e "negro" há uma ausência onde deveria estar a mulher negra, precisamente porque nem "mulher" nem "negro" a incluem. A interseção nos mostra um vazio (Lugones, 2008:2519).
\end{abstract}

Destarte, para Lugones (2008) é necessário empreender uma ressignificação da interseção, de modo que gênero e raça não apareçam mais separados; que sejam compreendidos em um todo

\footnotetext{
19 “[...] 'mujer' selecciona como norma a lashembras burguesas blancasheterosexuales, 'hombre' selecciona a machos burgueses blancosheterosexuales, 'negro' selecciona a machos heterosexuales negros y, así, sucesivamente. Entonces, se vuelvelógicamente claro que la lógica de separación categorial distorsionalos seres y fenómenos sociales que existenenlaintersección, como laviolencia contra lasmujeres de color. Dada laconstrucción de lascategorías, laintersección entre 'mujer' y 'negro' hay una ausencia donde debería estar lamujer negra precisamente porque ni 'mujer' ni 'negro' laincluyen. La intersección nos muestraunvacío" (Lugones, 2008:25).
} 
que constitui e é constituído pela colonialidade do poder. Segato, por sua vez, atentando-se às categorizações que são impostas no processo de formação nacional, convoca-nos a considerarmos

a densidade das diferenças culturais emergentes de antagonismos históricos complexos em cada nação e em cada região, que fazem, por exemplo, com que a percepção de negritude e de indigeneidade em cada um dos países do continente varie em função de lógicas histórias próprias. Ou seja, se trata de uma crítica a um mapa multicultural achatado e esquemático que desenha uma diversidade fixada no tempo, reificada em seus conteúdos e despojada das dialéticas que conferem historicidade, mobilidade e enraizamento local, regional e nacional $\left(2007: 20^{20}\right)$.

A partir dessa chamada crítica realizada pela antropóloga argentina, compreende-se a importância de se pensar as mais plurais formas de organização social e de vivência - construídas a partir da própria experiência palpável e não de imposições externas - para lograrmos uma luta feminista que abarque as demandas de mulheres não-brancas em espaço latino-americano. Dessa forma, torna-se exequível um feminismo decolonial, um feminismo amplo e crítico que desarticula os pressupostos de um movimento hegemônico de mulheres e que formula estratégias a partir da autonomia, geografia, história e cultura das mulheres dos países da América Latina (Mohanty, 2008:113).

A homogeneização dos grupos, isto é, as identidades políticas que emergem de categorizações que constroem ou desenvolvem, a um só tempo, raça e gênero, é precisamente aquilo que oculta as experiências das mulheres não-brancas. Sabe-se, portanto, que o feminismo quando toma formas hegemônicas, reproduz e retroalimenta um sistema de dupla violência contra as mulheres observado na construção de nossos discursos históricos. Vimos que a categorização dos sujeitos foi e é uma prática colonialista violenta que impõe formas de ver, compreender e contar nossas histórias. Se nos atentarmos a isso, veremos o quanto as mulheres não-brancas são silenciadas pela omissão de suas experiências nas formações nacionais latino-americanas e, então, compreenderemos a importância de se desestruturar, acima de tudo, o discurso racista e sexista em um mesmo nível - construtor da sociedade moderna, colonial/capitalista.

Segato elabora um importante estudo nesse sentido. Em La crítica de la colonialidad en ocho ensayos: y uma antropología por demanda (2013), o quinto capítulo, intitulado "El Edipo Negro: colonialidad y forclusión de género y raza", traz o debate sobre uma relação forcluída ${ }^{21}$ que estrutura a psique dos povos da América Latina, em especial os brasileiros considerados brancos: a parte materna e negra das famílias. Há uma tendência histórica - porque racista e misógina - de se construir a história das famílias "brancas", as quais constituem a elite dos países colonizados, desconsiderando e apagando o papel fundamental exercido por mulheres negras no próprio ordenamento das famílias. Quando citadas, são mistificadas em narrativas que tratam sobre a docilidade e ternura das amas-de-leite, em um movimento ideológico que visa tão só minimizar as violências da escravidão. É o que Segato lê como "um crime perfeito baudrillardiano". Para a teórica, "os aspectos exteriores da cena parecem preservar-se como uma casca ou epitélio, enquanto que aspectos determinantes de seu conteúdo são removidos e substituídos subrepticiamente por outros através de uma estratégia de verossimilitude" (Segato, 2013:195²2). Mais uma vez, nota-se o ocultamento da experiência real de mulheres não-brancas e a construção $e$ evocação de uma identidade global sobre negritude (ou não-branquitude, de maneira mais ampla) vinculada ao gênero e a qual serve aos desígnios coloniais/capitalistas de dominação e sujeição.

\footnotetext{
20 " [...] ladensidad de las diferencias culturales emergentes de antagonismos históricos complejosen cada nación y en cada región, que hacen, por ejemplo, que lapercepción de lanegritud y de laindianidaden cada uno de los países del continente varíeenfunción de lógicas históricas propias. O sea, se trata de una crítica a un mapa multicultural chato y esquemático que diseña una diversidadfijadaeneltiempo, reificada en sus contenidos y despojada de lasdialécticas que leconfierenhistoricidad, movilidad, y arraigo local, regional y nacional" (Segato, 2007:20).

${ }^{21}$ A forclusão diz respeito a um mecanismo de apagamento da psique. Elaborado por Lacan 1995 [1956], o conceito designa a rejeição de um significante basilar que é, então, projetado para fora do universo simbólico do sujeito.

22 "[...] los aspectos exteriores de laescenaparecenpreservarse como una cáscara o epitelio, mientras aspectos determinantes de sucontenidoson removidos y sustituidossubrepticiamente por otros a través de una estrategia de verosimilitud" (Segato, 2013:195).
} 
Rejeitados desenvolvimentos históricos como esses, gênero e raça se perdem enquanto práticas impostas, $e$ as lutas sociais, quando não se atentam a isso, correm o risco de reproduzirem essas "ausências" tão bem articuladas pela colonialidade do poder. Logo, a proposta de um feminismo decolonial passa pelo descortinamento de tais processos históricos - e contínuos - que tornam invisíveis as demandas de mulheres não-brancas.

Cabe notar, ainda, que os pontos de tensão entre as perspectivas de Lugones e Segato não embotam as práticas de um feminismo decolonial. Trazem, antes, aportes para uma discussão mais aprofundada das possibilidades de começo e fim da hierarquia de gênero observada $e$ vivida hoje dentro do sistema capitalista colonial/moderno. Para Lugones, o capitalismo eurocentrado global introjetou diferenças de gênero onde antes não existiam (2008:32). Respaldada pelo estudo elaborado por Oyéronké Oyewùmi (1997), a autora argumenta que o patriarcado não pode ser considerado uma estrutura transcultural autêntica, já que a sociedade Yoruba, por exemplo, não conhecia um sistema de gênero institucionalizado antes do início do processo de colonização ocidental. O gênero, categoria que, nessa perspectiva, teria sido introduzida pelo Ocidente nas culturas dos povos colonizados, é ferramenta importante de dominação que reafirma o binarismo e a hierarquia constitutiva do mundo colonial. Lugones (2008:34) ainda argumenta que, com a investida colonial, as mulheres pertencentes às comunidades colonizadas foram então excluídas dos papéis de liderança, perderam propriedades e outros espaços econômicos. A imposição do Estado de modelo Europeu foi a causa, de acordo com a autora, da degradação do status social das mulheres nesses espaços.

Divergindo dessa perspectiva, Rita Segato (2011:23) apresenta, a partir de suas investigações históricas e de relatos etnográficos, a proposta de que nas sociedades indígenas e afro-americanas anteriores à colonização existia um "patriarcado de baixo impacto". Isso significa que, ainda que o sistema de gênero não fosse exatamente como aquele desenvolvido e reproduzido pelo Ocidente, tais comunidades já experimentavam nomenclaturas de gênero. A antropóloga explica que

dados documentais, históricos e etnográficos do mundo tribal mostram a existência de estruturas reconhecíveis de diferença, semelhantes ao que chamamos de relações de gênero na modernidade, contendo claras hierarquias de prestígio entre masculinidade e feminilidade, representadas por figuras que podem ser entendidas como homens e mulheres. Apesar da natureza reconhecível das posições de gênero, as aberturas de tráfego e circulação entre as posições interditadas em seu equivalente ocidental moderno são mais frequentes naquele mundo (Segato, 2011:2323).

Em Las Estructuras Elementales de la Violencia (2003), Segato aborda a questão da construção da masculinidade que, segundo ela, acompanha o tempo da espécie - e, por isso, refere-se a uma "pré-história patriarcal da humanidade" (Segato, 2011:244 ${ }^{24}$ ). Entende-se por masculinidade uma identidade totalmente dependente de um status que "engloba, sintetiza $e$ confunde poder sexual, poder social e poder de morte" (Segato, 2003:3725). Assim, para atingir a masculinidade, é preciso que se passe por provas e por certos desafios que, algumas das vezes, vislumbram até mesmo a morte de um Outro - em sua maior recorrência, feminino. Esse "status masculino", estando na condição de ser adquirido e não orgânico, comporta o risco constante de ser perdido. Dessa forma, o sujeito sente a necessidade de assegurá-lo, reiterá-lo e restaurá-lo diariamente. Na concepção de Segato, esse status masculino não tem um "momento inicial", mas foi, antes, modificado ao longo do tempo. Isso quer dizer que o gênero já existia, porém tomou formas muito específicas a partir da imposição do sistema colonial/moderno. A autora, portanto, afirma que ao serem violentadas por esse sistema, as comunidades tribais tiveram suas

\footnotetext{
23 "Datosdocumentales, históricos y etnográficos del mundo tribal, muestranlaexistencia de estructurasreconocibles de diferencia, semejantes a lo que llamamos relaciones de género enlamodernidad, conteniendojerarquías claras de prestigio entre lamasculinidad y lafeminidad, representados por figuras que pueden ser entendidas como hombres y mujeres. A pesar del carácter reconocible de las posiciones de género, enese mundo son más frecuenteslas aberturas al tránsito y circulación entre esas posiciones que se encuentraninterdictasensu equivalente moderno occidental" (Segato, 2011:23).

24 "[...] prehistoria patriarcal de lahumanidad" (Segato, 2011:24).

25 "[...] engloba, sintetiza y confunde poder sexual, poder social y poder de muerte" (Segato, 2003:37).
} 
interpretações de gênero consideravelmente - e perigosamente - alteradas, de modo que a estrutura das relações é modificada e ressignificada dentro desses contextos. Compreende-se, então, que "as nomenclaturas permanecem, mas são reinterpretadas à luz da nova ordem moderna" (Segato, 2011:24 ${ }^{26}$ ).

Nesse sentido, as mudanças impostas trazem consequências letais: uma comunidade que já conhecia a nomenclatura de gênero e já experimentava formas hierárquicas, ao entrar em contato mediante usurpação e violência - com o discurso igualitário fictício e dissimulado da modernidade, passa a se organizar através de formas super-hierárquicas, principalmente devido a superinflação dos homens dessas comunidades, os quais passam a exercer um papel de intermediários com o mundo exterior (e branco). Além disso, observa-se a superinflação da esfera pública, a qual é habitada ancestralmente pelos homens, mas que se intumesce a partir do colapso e da privatização da esfera doméstica na modernidade/colonialidade (Segato, 2011). Uma das principais contribuições que essa concepção de Segato traz à formulação de um feminismo decolonial é a possibilidade de tornar explícita a experiências das mulheres não-brancas não apenas perante a sociedade branca, capitalista e moderna/colonial, mas também, e fundamentalmente, perante suas próprias comunidades, dentro das quais vivem em constante tensão. Em um mundo binário, tal qual o é o moderno, essas mulheres se veem como o Outro duplamente: porque não-brancas $e$ porque mulheres. Seria um duplo-duplo. Assim, "viver de forma decolonial é intentar abrir brechas em um território totalizado pelo esquema binário, que é possivelmente o instrumento mais eficiente do poder" (Segato, 2011:28 ${ }^{27}$ ). É isso, precisamente, o que a proposta de um feminismo decolonial objetiva.

\section{Considerações finais}

Neste breve estudo, pretendeu-se elaborar um debate acerca das possibilidades de desenvolvimento de um feminismo decolonial, o qual desponta da perspectiva da colonialidade do poder. A partir de uma proposta de leitura das produções de autoras e autores que se dispuseram a teorizar sobre o tema, viu-se que a colonialidade do poder caracteriza um momento de ruptura no pensamento crítico latino-americano, principalmente dentro dos campos da História, Filosofia e Ciências Sociais, ao mesmo tempo em que se mostra como uma compreensão de mundo que é capaz de reorientar as lutas políticas e os movimentos sociais organizados no contexto da América Latina (Segato, 2014).

Inicialmente, foi preciso caracterizar a teoria decolonial frente aos estudos pós-culturais. De acordo com Mignolo (2007:27), o que diferencia o pensamento decolonial do pós-cultural é a gênese de ambos; enquanto o último se origina no pós-estruturalismo francês, o primeiro emerge das Américas e tem uma história a nível mundial. A partir disso, argumentamos que o giro decolonial é um giro epistêmico, o qual se desenvolve mediante a necessidade de pensarmos a história dos países e dos povos colonizados fora das categorizações impostas pela matriz de poder colonial/moderna. Aníbal Quijano, um dos nomes pioneiros na reflexão sobre o tema, explica que a colonialidade do poder é o que faz com que esse sistema permaneça inquebrantável. Em sua visão, a colonialidade é um elemento constitutivo do padrão mundial de poder capitalista, e ela se funda exatamente na imposição de uma classificação da população do mundo em termos de raça e etnia (Quijano, 2007:93).

Essa imposição de classificação populacional corresponde ao que conhecemos como modernidade. A experiência da colonização e da colonialidade transformaram as relações intersubjetivas ao colocá-las frente ao capitalismo. A hegemonia da Europa foi, então, sendo construída dentro desse contexto, enquanto naturalizava as relações de poder que a garantia. Assim, vemos que o eurocentrismo nada mais é do que uma "perspectiva cognitiva de longo prazo de todo o mundo eurocentrado do capitalismo colonial/moderno, e que naturaliza a experiência das

\footnotetext{
26 “[...] las nomenclaturas permanecen, pero son reinterpretadas a la luz delnuevoorden moderno" (Segato, 2011:24).

27 " [...] vivir de forma descolonial es intentar abrir brechas enunterritorio totalizado por el esquema binario, que es posiblementeel instrumento más eficiente del poder" (Segato, 2011:28).
} 
pessoas nesse padrão de poder" (Quijano, 2007:94 ${ }^{28}$ ). Partindo das proposições de toda a teoria decolonial de que a criação e a imposição do conceito de raça é a maior categoria que comanda a divisão dos povos, o que permite a continuidade dessa racialização é, decerto, sua naturalização.

Esse processo de naturalização é, igualmente, dado em relação ao binarismo de gênero. Dessa forma, conforme ocorre com o racismo, o sexismo também se mostra como estrutura da sociedade regida pelo padrão colonial/moderno de poder. Em outros termos, o controle dos papéis de gênero e da sexualidade dos sujeitos é um dos eixos que se articulam dentro da matriz colonial de poder (Mignolo, 2008:8). É possível compreender, com isso, que as experiências das mulheres que ocupam espaços como a América Latina, os quais vivem ainda sob a colonialidade do poder, são múltiplas e particulares, não podendo ser equiparadas às de mulheres que - também em suas particularidades - correspondem à hegemonia construtora do padrão de poder.

Com base nesse pensamento, desenvolvemos uma crítica ao feminismo eurocêntrico-liberal por entendermos que ele não só não dá conta da multiplicidade de demandas de mulheres nãobrancas, mas, principalmente, porque ele pode aparecer como agente da colonialidade em um movimento que se pretende, desde os primórdios, emancipatório. $\mathrm{O}$ discurso sobre a universalidade, muito caro às perspectivas liberais, homogeneíza as experiências díspares, apagando vivências, principalmente, de mulheres não-brancas. Dessa maneira, percebe-se a impossibilidade de se pensar um movimento feminista que não intersecione raça, gênero e classe social - muito porque, como fora exposto, a divisão do trabalho responde à categorização da sociedade em termos de raça e gênero (Biroli, 2018). Ignorar as particularidades de experiências das mulheres, além de ser um ato violento, evidencia a continuidade da colonialidade. Assim, é mister que compreendamos que mesmo nas relações entre mulheres, quando lançamos um olhar interseccional, vemos um movimento em que umas terão privilégios sobre as outras. Apenas um entendimento crítico desse sistema poderá ser eficaz no sentido de ouvir as vozes silenciadas pelo padrão mundial de poder colonial/moderno.

Nesse viés, María Lugones (2008), uma das teóricas aqui apresentadas, enfatiza que o problema das categorias que homogeneízam os seres é que, além de atenderem à matriz de poder colonial, elas selecionam os dominantes do grupo como norma. Ou seja, em um grupo de "mulheres", a norma será branca, burguesa, heterossexual etc. Da mesma forma, Rita Segato (2011), outra expoente do feminismo decolonial, critica tais "identidades globais", já que estas se mostram fixas, dominadoras $e$ atendem tão somente aos interesses dos Estados modernos liberais/neoliberais. Logo, ambas as autoras convergem na crítica às categorizações impostas pelo eurocentrismo e, ademais, reproduzidas pelo feminismo hegemônico.

Entretanto, Lugones e Segato divergem quanto à gênese do binarismo de gênero nos países colonizados. Para a primeira, a questão de gênero foi imposta, pelos colonizadores europeus, em locais e comunidades que jamais tiveram contato com tais disparidades, como foi o caso dos Yorubas (Lugones, 2008:32). Já para Segato (2011:23), na verdade, sociedades como essas já conheciam nomenclaturas de gênero, embora estas não tivessem a mesma magnitude que tomaram após a invasão e colonização; o que havia era um "patriarcado de baixo impacto". O sistema de gênero para Segato, então, não possui um ponto zero na história.

Com base nessas discussões, torna-se possível pensar um feminismo decolonial, isto é, um feminismo que procure descentralizar e descategorizar, expondo as formas de colonialidade que mantém suas ações nas vidas de mulheres não-brancas. A decolonialidade mostra, enfim, a impossibilidade de se pensar o sistema de gênero fora do sistema de racialização e da divisão mundial de trabalho, eixos estes que sustentam, incansavelmente, o padrão atual de poder capitalista, colonialista e moderno.

\section{Referências bibliográficas}

BIROLI, Flávia. Gênero e desigualdades. os limites da democracia no Brasil. São Paulo, Boitempo, 2018.

\footnotetext{
28 " [...] la perspectiva cognitiva producidaenel largo tiempodel conjunto del mundo eurocentradodel capitalismo colonial/moderno, y que naturalizala experiencia de las gentes en este patrón de poder" (Quijano, 2007:94).
} 
BUTLER, Judith. Problemas de gênero: feminismo e subversão da identidade. 15. ed. Rio de Janeiro, Civilização Brasileira, 2017a. Tradução Renato Aguiar.

Relatar a si mesmo: crítica da violência ética. Belo Horizonte, Autêntica, 2017b. Tradução Rogério Bettoni.

CASTRO-GÓMEZ, Santiago. Latinoamericanismo, Modernidad, Globalización. Prolegómenos a una crítica poscolonial de larazón. In: ; MENDIETA, Eduardo (org.). Teoríassin disciplina: latinoamericanismo, poscolonialidad y globalizaciónen debate. Ciudad de México, Miguel Ángel Porrúa, 1998, pp.122-153.

; GROSFOGUEL, Ramón. Prólogo. Giro decolonial, teoría crítica y pensamientoheterárquico. In: (org.). El giro decolonial: reflexiones para una diversidad epistémica más alládel capitalismo global. Bogotá, Siglo del Hombre Editores; Universidad Central, Instituto de Estudios Sociales Contemporáneos y Pontificia Universidad Javeriana, Instituto Pensar, 2007, pp.9-24.

CORONIL, Fernando. Natureza do pós-colonialismo: do eurocentrismo ao globocentrismo. In: LANDER, Edgardo (org.). A colonialidade do saber. eurocentrismo e ciências sociais. Perspectivas latino-americanas. Buenos Aires, Colección Sur-Sur, CLACSO, 2005.

FEDERICI, Silvia. Calibã e a bruxa: mulheres, corpo e acumulação primitiva. São Paulo, Elefante, 2017. Tradução Coletivo Sycorax.

FERRARA, Jéssica Antunes. Literatura, gênero e política na América Latina: conexões entre Pagu e Blanca Luz. Dissertação (Mestrado em Estudos Literários), Universidade Federal de Juiz de Fora, 2019 [https://repositorio.ufff.br/jspui/handle/ufjf/9340 - acesso em: 10 out. 2019].

HALL, Stuart. Da Diáspora: Identidades e Mediações Culturais. Belo Horizonte, Editora UFMG; Brasília, Representação da UNESCO no Brasil, 2003.

LACAN, Jacques. O seminário, livro 4: a relação de objeto. Rio de Janeiro, Jorge Zahar, 1995 [1956].

LUGONES, María. Colonialidad y género: haciaun feminismo descolonial. In: MIGNOLO, Walter (comp.). Género y descolonialidad. Buenos Aires, Del Signo, 2008, pp.13-54.

MALDONADO-TORRES, Nelson. Against War. views from the underside of modernity. Durham/London, Duke University Press, 2006.

MIGNOLO, Walter D. El pensamiento decolonial: desprendimiento y apertura. Un manifiesto. In: CASTROGÓMEZ, Santiago; GROSFOGUEL, Ramón (org.). El giro decolonial: reflexiones para una diversidad epistémica más alládel capitalismo global. Bogotá, Siglo del Hombre Editores; Universidad Central, Instituto de Estudios Sociales Contemporáneos y Pontificia Universidad Javeriana, Instituto Pensar, 2007, pp.25-46.

Introducción: ¿̇cuáles son los temas de género y (des)colonialidad? In: descolonialidad. Buenos Aires, Del Signo, 2008, pp.7-12.

MIGUEL, Luis Felipe. A Igualdade e a Diferença. In: ; BIROLI, Flávia (org.). Feminismo e política: uma introdução. São Paulo, Boitempo, 2014, pp.63-78.

MIÑOSO, Yuderkys Espinosa. Etnocentrismo y colonialidad en los feminismos latinoamericanos: complicidades y consolidación de las hegemonías feministas en el espacio transnacional. Revista Venezolana de Estudios de la Mujer, Caracas, v. 14, n. 33, jul./dez, 2009, pp.37-54 [http://saber.ucv.ve/ojs/index.php/rev_vem/article/view/2064/0 - acesso em: 10 out. 2019].

MOHANTY, Chandra Talpade. Bajo losojos de occidente: feminismo académico y discursos coloniales. In: NAVAZ, Liliana Suárez; CASTILLO, Rosalva Aída Hernández (org.). Descolonizando el feminismo: teorías y prácticas desde losmárgenes. Madrid, Universitat de València, Instituto de lamujer, 2008, pp.112-161.

OYEWÙMI, Oyéronké. The invention of women: making an African sense of western gender discourses. Minneapolis,University of Minnesota Press, 1997.

PINTO, Céli Regina Jardim. Uma história do feminismo no Brasil. São Paulo, Fundação Perseu Abramo, 2003.

QUIJANO, Aníbal. Colonialidaddel poder, eurocentrismoy América Latina. In: PALERMO, Zulma; QUINTERO, Pablo (org.). Aníbal Quijano: textos de fundación. Buenos Aires, Del Signo, 2014a, pp.109158. 
iQué tal raza! In: PALERMO, Zulma; QUINTERO, Pablo (org.). Aníbal Quijano: textos de fundación. Buenos Aires, Del Signo, 2014b, pp.100-108.

Colonialidaddel poder y clasificación social. In: CASTRO-GÓMEZ, Santiago; GROSFOGUEL, Ramón (org.). El giro decolonial: reflexiones para una diversidad epistémica más alládel capitalismo global. Bogotá, Siglo del Hombre Editores; Universidad Central, Instituto de Estudios Sociales Contemporáneos y Pontificia Universidad Javeriana, Instituto Pensar, 2007, pp.93-126.

SEGATO, Rita L. Marco teórico de lamateria: la perspectiva teórico política de la crítica de lacolonialidad. In: Seminário Virtual Clacso (1903). Raza, género y derechos desde la perspectiva de lacolonialidad. Buenos Aires, CLACSO, 2019.

La perspectiva de lacolonialidaddel poder. In: PALERMO, Zulma; QUINTERO, Pablo (org.). Aníbal Quijano: textos de fundación. Buenos Aires, Del Signo, 2014, pp.15-43.

El Edipo Negro: colonialidad y forclusión de género y raza. In: La crítica de la colonialidad en ocho ensayos. y una antropología por demanda. Buenos Aires, Prometeo, 2013, pp.178-210.

Género, y Colonialidad: en busca de claves de lectura y de unvocabulario estratégico descolonial. In: BIDASECA, Karina (org.). Feminismos y poscolonialidad: descolonizando el feminismo desde y en América Latina. Buenos Aires, Godot, 2011, pp.17-47.

Introducción: políticas de laidentidad, diferencia y formacionesnacionales de alteridad. In: . La nación y sus otros. raza, etnicidad y diversidad religiosa entiempos de políticas de laidentidad. Buenos Aires: Prometeo, 2007, pp.15-36.

Las estructuras elementales de la violencia. Bernal, Universidad Nacional de Quilmes, 2003. 